\title{
Vulnerabilidade e a construção social do risco: uma contribuição para o planejamento na macrometrópole paulista
}

\author{
Vulnerability and the social construction of risk:
n to planning in the São Paulo Macrometropolis \\ Vulnerability and the social construction of risk:
a contribution to planning in the São Paulo Macrometropolis
}

Kátia Canil [I]

Andrea Lampis [II]

Kavê Lopes dos Santos [III]

\section{Resumo}

A partir da perspectiva das ciências sociais aplicadas, este artigo aborda o significado dos termos risco, desastre e vulnerabilidade, considerando sua compreensão e a necessidade de incorporá-los às diretrizes e às ações do planejamento na Macrometrópole Paulista (MMP) no contexto de variabilidade climática. Para garantir um entendimento aprofundado do que se denomina construção social do risco, urge considerar os aspectos físicos de dado espaço geográfico, pois nele são estabelecidas variadas formas de uso e de ocupação promovidas pela sociedade em dada conjuntura política e econômica. Dentre as diversas intervenções antropogênicas pelas quais a MMP tem passado, este artigo aborda o problema das inundações que atingem a área da MMP, mas especialmente daquelas ocupadas pelas populações em baixa renda, nas periferias urbanas.

Palavras-chave: vulnerabilidade; risco; inundação; Macrometropole Paulista; planejamento.

\begin{abstract}
Based on the perspective of the applied social sciences, this article addresses the meaning of risk, disaster and vulnerability, considering that they need to be understood and incorporated into the planning guidelines and actions for the São Paulo Macrometropolis in the context of climate variability. To ensure a deep understanding of what is called social construction of risk, it is necessary to consider the physical aspects of a given geographical space, since it is in this space that different forms of land use and occupation are promoted by society, within a given political and economic conjuncture. Among the several anthropogenic interventions the São Paulo Macrometropolis has undergone, this article addresses the problem of the floods that affect the region, focusing on areas occupied by low-income groups in urban peripheries.
\end{abstract}

Keywords: vulnerability; risk; floods; São Paulo Macrometropolis; planning. 


\section{Introdução: a construção social do risco, do desastre e da vulnerabilidade social}

Em seu conjunto, os riscos e os desastres formam um tópico tradicionalmente tematizado e problematizado pelas engenharias, pelas ciências naturais (geologia), pela geografia e, apenas mais recentemente, pelo planejamento, que tem abordado com pouca ênfase essa questão. Comumente fala-se em desastres naturais, separando-os das dinâmicas sociais e dos processos econômicos, políticos e culturais que transformam o espaço geográfico ao longo do processo histórico. Nos cenários de desastre, a população pode ser entendida como mais ou menos vulnerável. No entanto, para compreender os desastres e a vulnerabilidade social impingida neles, bem como a gestão de geração do risco e a compreensão da dinâmica dos processos físico-naturais, é necessário incluir processos sociais, econômicos e políticos.

0 primeiro avanço nesse sentido foi realizado pelo texto clássico de Blaikie et al. (1994) intitulado At risk. Nesse estudo, os autores apresentam o famoso modelo de pressão-liberação, no qual são mostradas as acumulações políticas, sociais e geográfico-espaciais da vulnerabilidade, de modo que a exposição - também em seu sentido mais material de proximidade - é só uns dos aspetos, ainda que mais visíveis, de toda a dinâmica. Mesmo que essa não seja uma nova perspectiva analítica, ela ainda se encontra inserida de forma marginal no Brasil (Londe et al., 2018; Marchezini et al., 2017), dada a impermeabilidade das instituições públicas, bem como as especificidades das instituições que tradicionalmente têm se ocupado dos desastres sem levar em conta, por um lado, a própria economia política do território nacional e, por outro, a economia política dos desastres; sendo umas das principais razões pela qual a compreensão dos desastres depende do conhecimento técnico e científico dos especialistas (Lampis, 2017).

Sob condições de risco, encontra-se grande parte das populações e comunidades que vivem em situação de vulnerabilidade, principalmente em grandes centros urbanos dos países da África, Ásia, América Latina e Caribe. Essa situação é produto dos modelos econômicos que prevalecem desde a metade do século XX e que, de um lado, promoveram o processo de desenvolvimento industrial e de expansão urbana acelerada, mas que, de outro, acentuaram as desigualdades econômicas e sociais, aumentando a pobreza e expulsando significativa parte da população para as periferias urbanas, áreas que foram gradativamente ocupadas de forma desordenada, o que gerou, não apenas problemas ambientais de diversas ordens, mas também a intensificação de situações de riscos geradas por ameaças ou processos naturais (Sassen, 2014; Dickson et al., 2012), que são incrementadas por eventos extremos decorrentes de mudanças climáticas.

Para entender esse contexto complexo, Blaikie e colegas (1996) fazem uma reflexão sobre o que consideram como progressão da vulnerabilidade, que tem origem nas causas profundas (modus operandi dos sistemas políticos e econômicos); nas pressões dinâmicas (fragilidades das instituições locais e das macroforças que levam às intervenções no uso e na ocupação do solo e impactos nos recursos hídricos); e nas condições inseguras (fragilidades dos ambientes naturais, baixas condições econômicas da população, existência de grupos mais vulneráveis e ausência e/ou deficiência do 
Estado no apoio às ações de preparação para enfrentar o desastre). Esse cenário exposto a uma condição de ameaça ou perigo (tanto de origem dos eventos da dinâmica da natureza: terremotos, tsunamis, inundações, deslizamentos de terra, furacões; quanto de origem tecnológica: explosões com substâncias químicas perigosas, nuvens tóxicas, vazamento e/ou derramamento de produtos químicos) é passível de gerar situações de riscos e desastres.

Em se tratando das ameaças de ordem ambiental (pela união de fatores naturais e sociais), os processos que resultam da ocorrência de eventos extremos, potencializados por ações antropogênicas, vêm nas últimas décadas atingindo muitas cidades em todos os continentes, como, por exemplo, o ciclone que atingiu a cidade de Beira, em Moçambique, em março de 2019, vitimando milhares de pessoas e destruindo a precária infraestrutura existente na região central, o que interrompeu a ligação com outras regiões do país. A situação do desastre foi agravada pela crise política e pela desorganização do Estado que demonstrou sua incapacidade para enfrentar a situação, necessitando de ajuda externa. Outros casos semelhantes podem ser mencionados por todo o Sul Global, como as temporadas de chuvas na Colômbia, no final de 2010, ou mesmo os cada vez mais frequentes furacões que atingem os países caribenhos nos meses de junho, julho e agosto.

No caso brasileiro, essa leitura se faz necessária especialmente sobre as suas periferias urbanas, áreas caracterizadas por condições inseguras de habitabilidade, criticidade no abastecimento de água e ausência de saneamento, onde vive a maioria da população de baixa renda. Nesses bairros, observam-se ainda numerosos conflitos socioambientais e limitações para o controle do crescimento, da mitigação e do gerenciamento do uso do solo. São áreas de segregação e injustiça socioespacial, que têm a situação agravada pelo aumento e pela frequência de eventos extremos associados à variabilidade climática regional e global, configurando situações de riscos e desastres.

Na Macrometrópole Paulista (MP), região analisada neste artigo, a forma historicamente concebida de ocupação do espaço geográfico associada a ocorrência de chuvas convectivas intensas (especialmente nos meses de verão), levaram aos deslizamentos de terra no município de Campos do Jordão em 1999 e em 2000; às inundações em várias cidades localizadas à margem do Rio Paraíba no ano 2000; aos deslizamentos de terra nos municípios de Santo André e São Bernardo do Campo em 2005; às inundações na bacia do rio Juquery (que atingiram os municípios de Franco da Rocha e Caieiras) em março de 2016; aos deslizamentos em Mairiporã, Ribeirão Pires e Mauá; e às inundações na bacia do rio Tamanduateí (entre os meses de fevereiro e março de 2019). Os exemplos são numerosos e, apesar de os municípios auxiliados pelo Estado possuírem mecanismos para o atendimento às emergências e às situações de crise, passado esse momento, eles mantêm as condições de precariedade de seus territórios, quando não acentuam ainda mais a injustiça social.

Neste artigo, coloca-se, então, a questão de como inserir o tema de riscos e desastres dentro da proposta de um planejamento territorial com vistas a ações de curto, médio e longo prazo e que tenham como metas a redução das vulnerabilidades e o enfrentamento de suas causas profundas.

Põe-se, assim, um grande desafio que requer uma mudança de paradigma e de políticas 
de Estado e não apenas de governo. Contudo, considerando que tal mudança seja produto de um longo e contínuo processo, muitas iniciativas podem partir em função das leis já aprovadas, tais como o Estatuto das Cidades (lei federal n. 10.257/2001) (Brasil, 2001), o Estatuto da Metrópole (lei federal n. 13.089/2015) (Brasil, 2015) e a aplicação de seus respectivos instrumentos; e da própria lei n. 12.608/2012 (que trata da Política Nacional de Proteção e Defesa Civil - PNPDEC, mas ainda não regulamentada) (Brasil, 2012) e do Plano Nacional de Gestão de Riscos e Respostas a Desastres aprovado em 2012, que estabeleceu quatro eixos de atuação: mapeamento das áreas de risco; estruturação do sistema de monitoramento e alerta; obras estruturantes do Ministério das Cidades; e fortalecimento dos órgãos de defesa civil via Sedec - Secretaria Nacional de Defesa Civil.

Porém, com a crise política do Estado brasileiro, que culminou com o impeachment do governo da presidenta Dilma Rousseff, em 2016, e sua substituição pelo governo de Michel Temer no mesmo ano, as políticas para gestão de riscos foram notoriamente enfraquecidas. Na atualidade, a PNPDEC está centrada no Ministério de Desenvolvimento Regional e está direcionada às ações de atendimento emergencial aos desastres. As perspectivas para a integração da gestão de riscos ao planejamento urbano territorial ainda não estão claramente estabelecidas, mas já há algumas ações em andamento.

No entanto, as políticas internacionais por meio do Marco de Sendai para Redução de Riscos e Desastres 2015-2030 são um reforço para ações no nível nacional. Esse marco apresenta quatro prioridades de ação: entender o risco de desastres; fortalecer a governança do risco de desastres para gerenciá-lo; investir na redução do risco para resiliência; e melhorar a preparação para respostas mais eficazes e propostas de melhores alternativas para reconstrução de áreas atingidas (UNISDR, 2019). A Agenda 2015-2030 para o Desenvolvimento Sustentável com seus 17 objetivos propostos pelas Nações Unidas (United Nations, 2019) também tem sido um elemento guia para que os países desenvolvam projetos para cumprir as metas previstas, buscando caminhos para a sustentabilidade e a resiliência, de modo que várias iniciativas por parte das cidades brasileiras são confirmadas em suas agendas, a exemplo do município de Santana de Parnaíba na Região Metropolitana de São Paulo.

Diante do cenário político e socioeconômico brasileiro e das políticas nacionais e internacionais que pautam a gestão de riscos e desastres, faz-se uma leitura inicial, destacando aspectos importantes que tratam da produção social do risco, da vulnerabilidade e como a questão vem sendo abordada dentro da MMP, sob o olhar do planejamento territorial.

\section{Qualificando a vulnerabilidade aos desastres: vulnerabilidade resultante e inerente}

O campo da gestão do risco de desastres e da análise da vulnerabilidade pode ser pensado como um terreno altamente fragmentado conceitual e politicamente. As definições de vulnerabilidade resultantes de uma vasta revisão da literatura existente (Adger, 2006 e Brooks, 2003) levam a identificar dois aspectos diferentes e complementares do termo. 
- Em uma delas, a vulnerabilidade é definida como a quantidade (ou potencial) de dano a um sistema para uma determinada ameaça climática.

- Na outra, a vulnerabilidade é entendida como um processo relacionado às condições internas ou ao estado de um sistema antes de enfrentar um evento relacionado a uma determinada ameaça.

Como ilustrado na Figura 1, essas duas conceituações de vulnerabilidade refletem duas visões divergentes não só técnica, mas também política. A opção por adotar um desses conceitos em detrimento do outro influencia de maneira fundamental a forma como entendemos e medimos a vulnerabilidade de um sistema, interferindo diretamente no tipo de intervenção política planejada para agir sobre a própria vulnerabilidade.

No primeiro caso, fala-se em vulnerabilidade biofísica (ou vulnerabilidade resultante), que é abordagem privilegiada pela tecnocracia da gestão administrativa dos territórios, empregada quando o que interessa é entender os resultados finais do impacto de um fenômeno em termos de vidas, perdas e danos. A pergunta que se faz, nesse caso, é "quanto um sistema é vulnerável a uma ameaça $X$ ou $Y$ ?". Essa abordagem de vulnerabilidade sobrepõe-se amplamente a outra, que predomina na concepção das ações para redução de riscos de desastres (do original em inglês Disaster Risk Reduction, DRR).

No segundo caso, fala-se em vulnerabilidade inerente, quando o foco é a compreensão dos fatores internos de um sistema que o torna vulnerável às ameaças. Nesse caso, questiona-se "por que esse sistema é vulnerável?". Essa abordagem é própria da linha da economia política dos desastres (Neumayer Plumper e Barthel, 2014), de modo que o conceito de vulnerabilidade social se origina pelos modelos socioeconômicos, e, portanto, o risco e o desastre são processos construídos socialmente e politicamente. Assim, os estudos sobre vulnerabilidade social (e os meios de vida) foram sistematizados ao longo das décadas entre 1970 e 1990, período em que tais abordagens foram se tornando gradativamente consagradas no âmbito internacional.

A compreensão dos riscos e desastres e suas abordagens relativas, o processo de gestão e o conceito de vulnerabilidade vêm evoluindo desde a década de 1940, quando emergiu a abordagem emergencial fundamentada nas lições estratégicas da Segunda Guerra Mundial, tendo em vista que os atores militares foram estruturando e sistematizando as ações focadas às emergências (Oliver-Smith, 1991). Nas décadas seguintes, as posições epistemológicas e as práticas na política de gestão do risco de desastres foram se consolidando e ainda hoje em dia dominam o panorama desse campo (Lampis, 2013). A partir da década de 1970 foi sendo definida a abordagem do ciclo do desastre, muito focada ainda no pós-desastre e articulada nas fases da emergência, ajuda humanitária e recuperação. Os anos 1980 são testemunha da chegada das abordagens elaboradas pelo conhecimento técnico e disciplinador da engenharia, com seu fluxo de fases estruturadas e analiticamente separadas dos preparativos pré-desastre, a prevenção, seguidos pelas intervenção de mitigação (às vezes identificadas como "ações corretivas do risco" até onde existe risco aceitável, como se humanamente existissem um risco bom e outro mau) e as ações de atenção a emergência 
Figura 1 - Dois conceitos da vulnerabilidade:

biofísica (ou resultante) e social (ou inerente) ${ }^{1}$

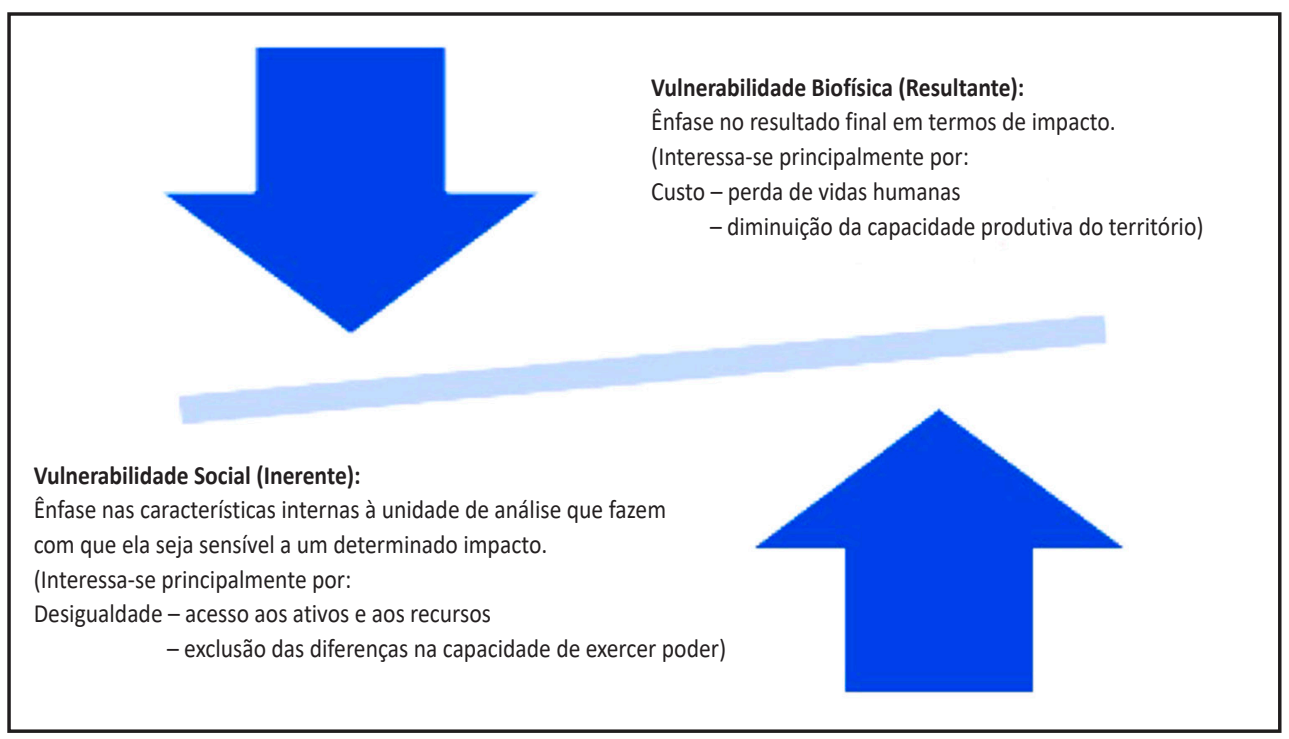

Fonte: adaptado de Lampis (2013).

e recuperação (em relação à infraestrutura das edificações) já propostas pela abordagem emergencial precedente.

Nos anos 1990, assistiu-se à chegada das ciências sociais na análise e na gestão dos desastres, valendo-se de todo o peso das contribuições da antropologia, da sociologia e das ciências sociais aplicadas. Ao mesmo tempo, uma renovada atenção das ciências exatas ao tema da vulnerabilidade gerou encontros e desencontros, os quais podem ser traduzidos pelas diferenças e complementaridades conceituais ilustradas anteriormente.
A partir dos anos 2000 vai se desenvolvendo uma abordagem muito institucionalizada na qual, com base no reconhecimento da centralidade da mudança climática e da necessidade de uma conceitualização mais integrada e transdisciplinar posta na relação entre risco, vulnerabilidade e mudança climática, foram feitos esforços no sentido de integrar diferentes abordagens das ciências exatas e sociais.

0 resultado dessa proposta não é de operacionalização simples; o debate entre a abordagem da gestão de risco e de desastre e os métodos científicos empregados no âmbito 
das pesquisas do IPCC demonstram a dificuldade de trabalhar com os conceitos para se chegar a um abordagem integrada sobre risco, desastre e vulnerabilidade (Füssel, 2010; IPCC, 2012; Lampis, 2013).

Um modo de esclarecer a complexidade dos debates sobre risco e vulnerabilidade é realizar uma análise das heranças conceituais e políticas de suas relativas abordagens. Muitos artigos sobre vulnerabilidade, gestão de risco e desastre e mudança climática começam o debate citando resultados de uma diversidade de pesquisas com muitas definições a partir de várias correntes de pensamento (Brooks, 2003; Chardon, 2010; Füssel et al., 2017; Lampis, 2013, 2018). Assim, o Quadro 1 apresenta uma análise de três correntes, explicitadas a seguir.

I) Risco-Ameaça (RA): corrente focada nos aspectos que produzem a vulnerabilidade, ou seja, o risco material e a ameaça física no sentido da exposição e da proximidade, orientando seu interesse para a probabilidade de risco, bem como para a quantificação de seu impacto.

II) Construção Social do Risco (CSR): corrente interessada nas condições de indivíduos, grupos e comunidades em relação ao estresse ao longo do tempo e eventos críticos específicos de origem externa. Ela privilegia a investigação dos fatores que aumentam a capacidade dos grupos humanos de enfrentar situações críticas e a recuperação de seus efeitos.

III) Abordagem Integrada (AI): interessa-se pela relação entre território e ameaça e busca integrar as duas abordagens anteriores.

Quando a atenção é focada na vulnerabilidade do ponto de vista biofísico, principalmente, o que é capturado é o que se manifesta no curto prazo, ou seja, eventos e seu impacto no território. Essa é a ênfase que mais atrai o pesquisador interessado em gerenciamento de riscos e é a que inspira o formulador de políticas. Isso é compreensível, no caso de estimar probabilidades e gerenciar riscos, embora seja crítico quando não considera a codeterminação de riscos por fatores sociais, políticos e culturais, além da biofísica. No entanto, a crítica mais importante a essa abordagem é a seguinte: quando as tendências climáticas futuras se manifestarem diferentemente do que é esperado (ou foi previsto pela análise de risco: por exemplo, aumento de eventos extremos, etc.), muito do que foi feito em termos de adaptação corre "o risco" de se tornar uma fonte de má adaptação.

Sob essa perspectiva, uma questão interessante diz respeito à possibilidade de passar de uma abordagem de risco (focada na geração de capacidade para prever danos) para outra perspectiva focada na criação de capacidade de resiliência no contexto daqueles cenários caracterizados pela incerteza. Nesse caso, não se trata apenas de conceitos e métodos de mensuração, mas de uma questão de filosofia do conhecimento em relação ao objetivo da pesquisa e à produção de conhecimento. Como alternativa, o que precisa ser fortalecido não é tanto a capacidade de evitar riscos (gerenciamento de perspectiva de risco na abordagem abrangente de gerenciamento de riscos), mas a capacidade de sistemas em diferentes escalas (país, região, comunidade, casa) absorver choques com o menor dano possível e fortalecer a própria capacidade de se recuperar de uma situação anterior ao acidente ou de se adaptar a novas condições. 
Quadro 1 - Sistematização dos principais enfoques da vulnerabilidade

\begin{tabular}{|c|c|c|c|}
\hline & Risco-Ameaça & Construção Social do Risco & Abordagem Sistêmica \\
\hline $\begin{array}{l}\text { Alcance da política em } \\
\text { relação à mudança } \\
\text { climática }\end{array}$ & $\begin{array}{l}\text { Mitigação do efeito dos } \\
\text { desastres, compensação } \\
\text { material e econômica }\end{array}$ & Adaptação dos grupos sociais & $\begin{array}{l}\text { Adaptação dos sistemas } \\
\text { físicos e sociais e dos } \\
\text { ecossistemas }\end{array}$ \\
\hline Problema principal & $\begin{array}{l}\text { O desastre como evento } \\
\text { natural e o risco associado } \\
\text { a ele }\end{array}$ & A vulnerabilidade social & $\begin{array}{l}\text { A vulnerabilidade dos } \\
\text { sistemas humano-naturais } \\
\text { em relação à mudança } \\
\text { climática e aos eventos } \\
\text { hidrometeorológicos } \\
\text { extremos }\end{array}$ \\
\hline $\begin{array}{l}\text { Pergunta de política } \\
\text { pública aplicada }\end{array}$ & $\begin{array}{l}\text { Qual é o risco associado } \\
\text { com os efeitos da mudança } \\
\text { climática, inclusive os } \\
\text { eventos hidrometeorológicos } \\
\text { extremos? }\end{array}$ & $\begin{array}{l}\text { Como se pode reduzir a } \\
\text { vulnerabilidade social das } \\
\text { sociedades e os grupos } \\
\text { humanos diante das } \\
\text { ameaças? }\end{array}$ & $\begin{array}{l}\text { Como se pode aumentar } \\
\text { a resiliência dos sistemas } \\
\text { socioecológicos? }\end{array}$ \\
\hline Objetivo principal & $\begin{array}{l}\text { Previsão e estimativa } \\
\text { quantitativa }\end{array}$ & $\begin{array}{l}\text { Explicação e transformação } \\
\text { política }\end{array}$ & $\begin{array}{l}\text { Antecipação e aumento da } \\
\text { resiliência dos sistemas }\end{array}$ \\
\hline $\begin{array}{l}\text { Significado de } \\
\text { vulnerabilidade }\end{array}$ & $\begin{array}{l}\text { A probabilidade (estimativa) } \\
\text { relativa ao dano associada } \\
\text { aos níveis determinados de } \\
\text { ameaça e vulnerabilidade }\end{array}$ & $\begin{array}{l}\text { A suscetibilidade determinada } \\
\text { por fatores socioeconômicos } \\
\text { ante diferentes tipologias de } \\
\text { ameaça }\end{array}$ & $\begin{array}{l}\text { O risco relacionado ao efeito } \\
\text { esperado a partir de cenários } \\
\text { diferentes de mudanças } \\
\text { climáticas }\end{array}$ \\
\hline Domínio & Os sistemas físicos & Os sistemas sociais & Os sistemas socioecológicos \\
\hline $\begin{array}{l}\text { Vulnerabilidade } \\
\text { e capacidade de } \\
\text { adaptação }\end{array}$ & $\begin{array}{l}\text { Não se encontra uma } \\
\text { verdadeira conceitualização. } \\
\text { A relação (V-CA) fica focada } \\
\text { na capacidade de resposta; } \\
\text { não considera os processos } \\
\text { contínuos (espaço e tempo) }\end{array}$ & $\begin{array}{l}\text { A vulnerabilidade determina a } \\
\text { capacidade de adaptação }\end{array}$ & $\begin{array}{l}\text { A capacidade de adaptação } \\
\text { determina a vulnerabilidade } \\
\text { futura (a qual, finalmente } \\
\text { através da sensibilidade, é } \\
\text { o conceito central porque } \\
\text { determina a resiliência) }\end{array}$ \\
\hline $\begin{array}{l}\text { De que se está falando } \\
\text { quando se menciona } \\
\text { a capacidade de } \\
\text { adaptação? }\end{array}$ & $\begin{array}{l}\text { A capacidade de resposta } \\
\text { diante de eventos naturais e } \\
\text { o risco associado a eles }\end{array}$ & $\begin{array}{l}\text { A adaptação à vulnerabilidade } \\
\text { gerada pela mudança } \\
\text { climática (exemplo: dupla } \\
\text { exposição) }\end{array}$ & $\begin{array}{l}\text { A adaptação ante a } \\
\text { vulnerabilidade futura em } \\
\text { relação à mudança climática }\end{array}$ \\
\hline $\begin{array}{l}\text { De onde começa } \\
\text { a análise desta } \\
\text { abordagem? }\end{array}$ & Cenários de ameaça & $\begin{array}{l}\text { Estresse e eventos críticos } \\
\text { que representam um choque } \\
\text { no presente (econômico, } \\
\text { social e ambiental) }\end{array}$ & $\begin{array}{l}\text { Cenários de mudança } \\
\text { climática e ameaças } \\
\text { relacionadas com a mudança } \\
\text { climática }\end{array}$ \\
\hline $\begin{array}{l}\text { Principais áreas do } \\
\text { conhecimento }\end{array}$ & $\begin{array}{l}\text { Ciências Exatas (engenharia, } \\
\text { física) }\end{array}$ & $\begin{array}{l}\text { Ciências Humanas (ciências } \\
\text { sociais) }\end{array}$ & $\begin{array}{l}\text { Ciências Exatas e Humanas } \\
\text { (engenharia, geologia, } \\
\text { geografia, ciências sociais, } \\
\text { gestão ambiental) }\end{array}$ \\
\hline
\end{tabular}

Fonte: Adaptado de Lampis (2013).

Uma vez levantado, analisado e sistematizado o debate acerca da produção social do risco e da vulnerabilidade social, interessa agora entender como a Macrometrópole Paulista, em toda a sua complexidade físico-natural, social, econômica e política, é uma região marcada por diversas situações de vulnerabilidade social e que, na conjuntura sociopolítica e climática contemporânea, está exposta de diferentes formas ao risco e ao desastre. 


\section{Dimensões espaciais da vulnerabilidade social e dos aspectos físicos na MMP}

A Macrometropole Paulista (MMP) é formada por 174 municípios - os quais abrangem as regiões metropolitanas de São Paulo, Campinas, Baixada Santista, Vale do Paraíba, Litoral Norte e Sorocaba, além das Aglomerações Urbanas de Jundiaí e Piracicaba e a Microrregião Bragantina -, que configuram uma área de aproximadamente 53 mil km² localizada na porção sudeste do estado de São Paulo (Figura 2). A MMP possui cerca de 33 milhões de habitantes, que vivem concentrados, sobretudo, nas áreas urbanas, segundo a taxa de urbanização da região que é de 94,8\% (Emplasa, 2019).

De maneira gradativa, essa região tem se tornado mais estudada pela comunidade científica, especialmente por geógrafos, sociólogos, economistas urbanistas e ambientalistas (Lencioni, 2015; Jacobi, Cibim e Leão, 2015; Richter e Jacobi, 2018; Tavares, 2018; Pasternack e Bógus, 2019), que debruçam seus esforços de análise nas múltiplas manifestações de ordem espacial, social, econômica, urbana e ambiental da área em questão.

A MMP pode ser entendida também como a expressão máxima da chamada região concentrada (Santos e Silveira, 2001), sobretudo por adensar um conjunto de infraestruturas

Figura 2 - Regiões Metropolitanas na Macrometrópole Paulista

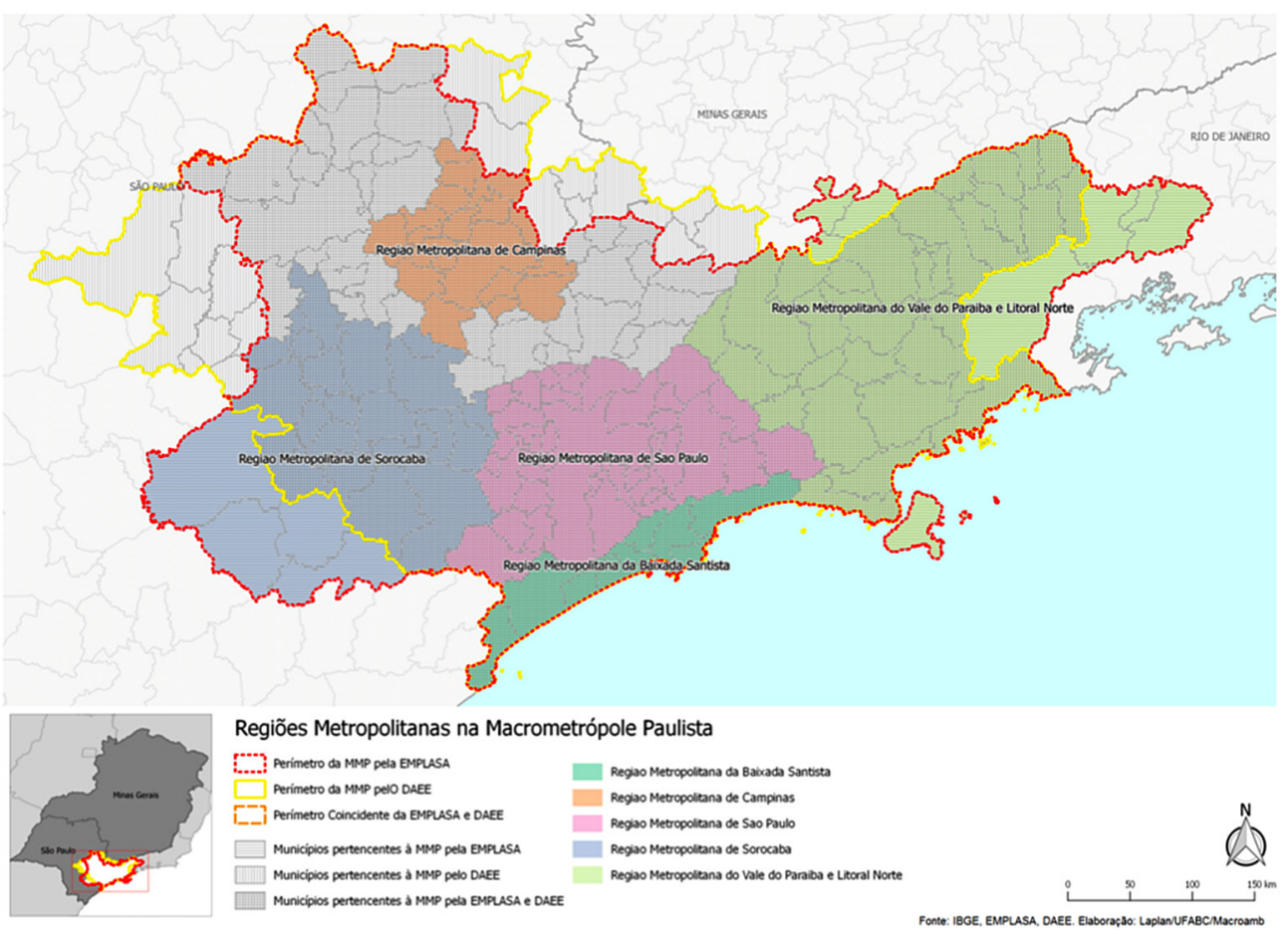

Elaboração: Laplan/ UFABC/ Macroamb, 2019. Fonte: IBGE, Emplasa, Daee. 
que tornaram a sua economia a mais dinâmica e moderna do País: nela, estão presentes as indústrias de alta tecnologia, o comércio e os serviços complexos e diversificados, a agroindústria de alta produtividade, os maiores e mais eficientes sistemas de transporte e distribuição, além de alguns dos principais polos científicos e de inovação da América Latina.

Como resultado disso, a MMP foi responsável, no ano de 2016, pela geração de 1,6 trilhão de reais, o equivalente a $25 \%$ do Produto Interno Bruto (PIB) brasileiro (Emplasa, 2019). De acordo com Tavares (2018), a região:

Apresenta um consolidado sistema urbano macrocefálico com centros de segunda ordem que orbitam ao seu redor articulados em rede por infraestrutura logística (rodoviária, ferroviária, portuária e aeroviária), energética, de comunicação e informacional; detentora dos melhores índices de desenvolvimento do país e concentradora das principais atividades produtivas do setor industrial, de serviços e inovação. Em relação à infraestrutura, nela se localiza o Porto de Santos que detém $25 \%$ do movimento de exportações e importações do país; o Aeroporto Internacional de Guarulhos que movimentou 39,5 milhões de passageiros em 2014 e é origem das principais rodovias estaduais e federais (rodovia Dutra, Ayrton Senna, Anchieta, dos Imigrantes, Regis Bittencourt, Anhanguera, Bandeirantes, Washington Luís, Castelo Branco, Raposo Tavares, Rodoanel) [...]. É a maior evidência da urbanização dispersa brasileira e se consolida como uma região com grandes contrastes sociais e territoriais. Sua origem remete-se à interiorização industrial e administrativa e ao processo de urbanização que a tornou a área mais urbana do país. Encontra-se na região paulista historicamente mais atendida pelos recursos públicos e privados, mas se destaca dela por concentrar maior renda e nível de desenvolvimento (Tavares, 2015). Não possui reconhecimento legal, mas de fato e sua definição teórico-conceitual bem como físico-administrativa tem sido constantemente revisada e complementada em função dos debates técnicos e políticos. (pp. 117-118)

Tal centralidade econômica da MMP é produto do vigoroso processo de industrialização nacional, ocorrido principalmente na região Sudeste entre as décadas de 1930 e 1980 (Furtado, 1976; Rangel, 1985; Mamigonian, 1999). Garantindo a modernização tecnológica de muitos setores econômicos para além da indústria - como a agricultura e as atividades de comércio e serviços, além das infraestruturas -, esse processo gerou um expressivo adensamento demográfico na região, alimentado por consistentes fluxos migratórios de brasileiros de diferentes partes do País, em especial dos estados do Nordeste e Minas Gerais, que procuravam melhores condições de vida por meio do empregos no setor secundário e, mais tarde, também no setor terciário, já que a indústria não absorveu a totalidade de oferta de força de trabalho do período em questão.

Em função de suas condições financeiras, essa população de baixo poder aquisitivo passou a viver nas periferias urbanas, áreas que expandiram horizontalmente em arranjos espaciais marcados pela precariedade de acesso a infraestruturas e serviços básicos, aspectos que geraram contrastes com a riqueza e a modernidade dos bairros centrais, 
que são áreas econômicas mais dinâmicas (Durham, 2004; Maricato, 1996; Kowarick, 2009; Villaça, 1998).

Nesse processo, a população urbana de baixa renda foi sendo gradativamente alocada nas fímbrias urbanas em função dos altos custos do preço do solo nas áreas centrais, dotadas de infraestruturas e serviços públicos. Diversos autores apontam para a parceria entre o Estado e as empresas do setor imobiliário na produção da exclusão social urbana nas cidades brasileiras (Maricato, 1996; Ferreira, 2007; Rolnik, 1998).

Assim, a MMP, ao mesmo tempo que se tornou uma das principais centralidades econômicas da América Latina, concentra, na atualidade, 2,68 milhões de habitantes que vivem em assentamentos precários e que são, certamente, a população mais vulnerável aos múltiplos riscos. Em outras palavras, pode-se considerar que, para além da vulnerabilidade social existente na região (Figura 3) - e que pode ser mensurada por meio de variáveis quantitativas e qualitativas, como rendimento familiar e acesso à moradia, às infraestruturas e aos serviços urbanos de qualidade -, acrescenta-se, ainda, a variável ambiental, intimamente relacionada às formas com que a sociedade estabelece suas relações com o espaço físico-biótico, ou seja, com o relevo, os corpos hídricos, o clima e a vegetação.

Figura 3 - Vulnerabilidade social na Macrometrópole Paulista - 2019

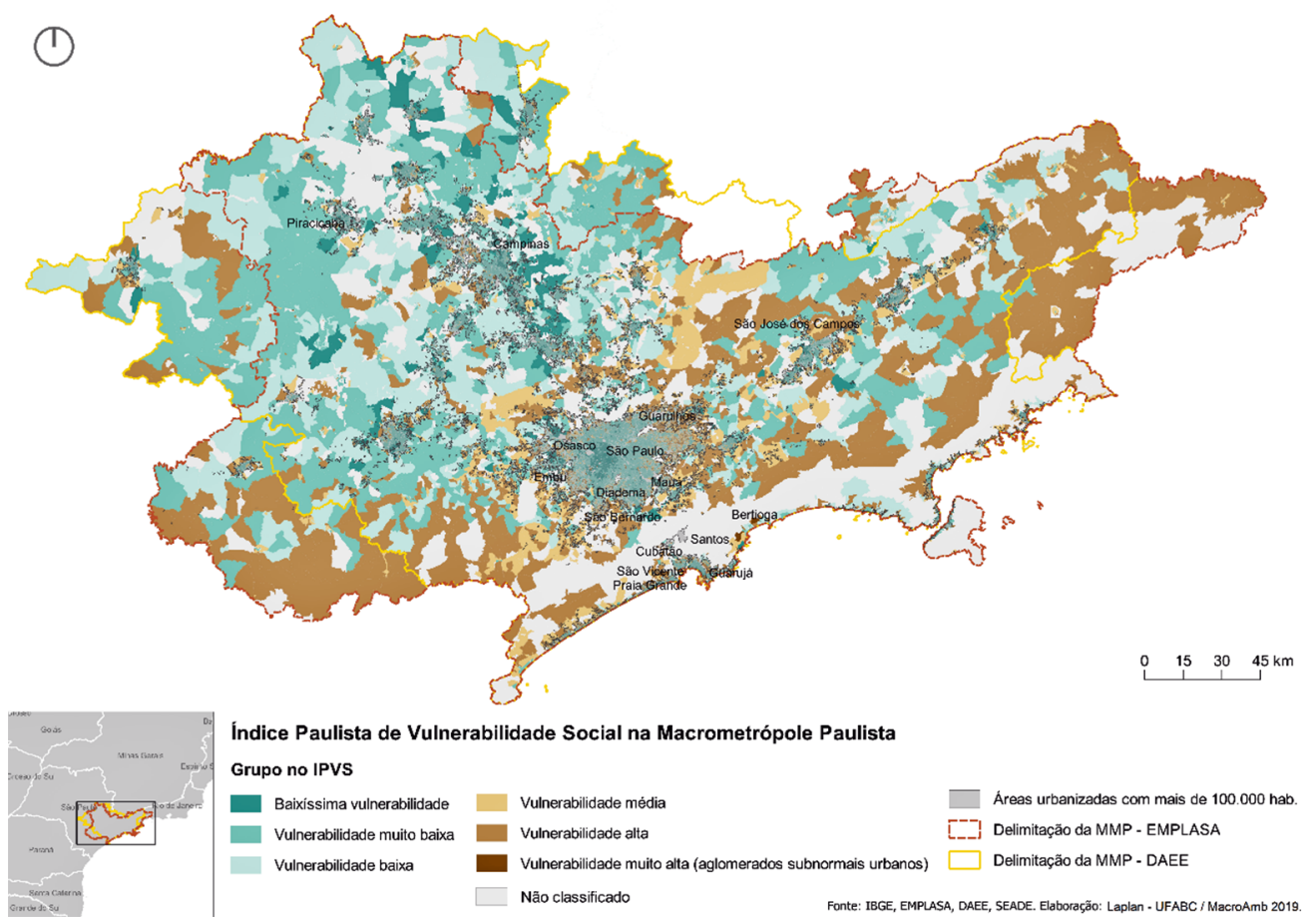

Elaboração: Laplan/ UFABC/ Macroamb, 2019. Fonte: IBGE, Emplasa, Daee. 
Pela análise dos aspectos do meio físico, a região da MMP abrange porções das províncias geomorfológicas da Planície Costeira, Planalto Atlântico e Depressão Periférica. Iniciando pelo litoral, a Província Costeira abrange os municípios da Baixada Santista e do Litoral Norte, considerando apenas os que fazem parte da MMP. É formada por sedimentos continentais e litorâneos. Possui ambientes extremamente frágeis e ricos em biodiversidade e são áreas suscetíveis a inundações periódicas (Ross e Moroz, 2011).

A província do Planalto Atlântico possui níveis altimétricos superiores aos 700 metros acima do nível do mar, sustentados por diversos tipos litológicos, predominando rochas metamórficas associadas às magmáticas intrusivas. Na extensão desse planalto, evidenciam-se unidades geomorfológicas distintas, considerando as formas e as declividades das vertentes e o padrão e a densidade da rede de drenagem (Ross e Moroz, 2011). São áreas predominantemente suscetíveis a movimentos gravitacionais de massa, principalmente os deslizamentos, com um alto índice de registros de eventos que provocaram danos à integridade física da população e à infraestrutura de forma geral. As planícies dos rios Tietê e Paraíba do Sul encontram-se "embutidas" nessa província geomorfológica, preenchidas por sedimentos que caracterizam as Bacias Sedimentares Cenozoicas. São áreas de alta suscetibilidade a processos de inundação, o que confere severos impactos em muitas cidades da MMP (Figura 4), (Moura, Canil e Sulaiman, 2019).

A Província Geomorfológica da Depressão Periférica Paulista, ocupando uma área significativamente menos expressiva, parte das regiões metropolitanas de Sorocaba e Campinas, nas porções oeste e norte da região, respectivamente, está estruturada sobre a Bacia Sedimentar do Paraná. Apresenta altitudes que oscilam entre 600 e 750 m e feições de relevo com médias a baixas declividade (Ross e Moroz, 2011). Na região, são mais representativos os processos de erosão hídrica.

A descrição das províncias geomorfológicas e seus processos associados serve para contextualizar o panorama dos aspectos físico-naturais ou geológico-geomorfológicos no qual estão estabelecidos os municípios da MMP e seu contingente populacional. Ocorrências de deslizamentos, erosão e inundações são inerentes às condições do meio físico, também denominadas "ameaças" ou "perigo" ou "hazards", porém em grande parte são agravadas pelas intervenções antrópicas nesse território. Compreender a dinâmica dos processos é fundamental para estabelecer ações de prevenção e mitigação para as áreas mais atingidas. Porém, não seria apenas um olhar técnico (vulnerabilidade biofísica - resultante); é fundamental considerar a vulnerabilidade social (inerente) das populações que habitam os espaços suscetíveis a esses processos. E, então, retorna-se a reflexão de Blaikie et al. (1996), compreensão dos riscos e desastres a partir das causas profundas, pressões dinâmicas e condições inseguras. À luz dessa leitura, toma-se como exemplo o histórico de ocorrências de inundações e seus desdobramentos e impactos na região da MMP.

Os rios da MMP - importantes vetores de ocupação ao longo da história - ajudaram a modelar o relevo da região, junto à erosão provocada pelo vento e pelas chuvas. Em algumas porções de menor declividade, a hidrografia da região criou planícies de alagamento, nas quais ocorria a deposição de sedimentos oriundos das áreas mais altas. 
Essas planícies - áreas nas quais as dinâmicas de alagamentos eram comuns à medida que o volume de água do fluxo dos rios e mananciais excedia o nível de saturação hidrostático, espacialmente nos meses de alta pluviosidade - tornaram-se significativamente ocupadas ao longo do século XX em muitas áreas da atual MMP, com destaque para os rios Tietê, Pinheiros (e seus mananciais) e Paraíba do Sul.

Essa ocupação esteve associada às práticas de agricultura irrigada (como a cultura do arroz no Vale do Paraíba) e pecuária; de transporte (com a utilização dos rios como hidrovia ou com a canalização de seu leito para dar origem às vias expressas, como as marginais do rio Tietê e Pinheiros); de produção de energia em pequenas hidrelétricas; além da edificação de diferentes tipos, especialmente de moradias (Martins, 2006).

Nesse cenário, a recorrência das inundações - fenômenos que já ocorriam em função das condições geomorfológicas, hidrográficas e climáticas da região - ganha dimensão no campo social, econômico e político, dado que se torna um problema urbano, capaz, inclusive, de intensificar a vulnerabilidade da população na MMP, sobretudo nas regiões metropolitanas de São Paulo e São José dos Campos.

O estudo nas planícies fluviais da RMSP, realizado por Rodrigues (2015), partiu de uma abordagem antropogeomorfológica, que considera a reconstrução do processo histórico da apropriação desses espaços, que levaram à ocorrência de impactos nos serviços ambientais, gerando situações de risco que foram consideradas nos marcos regulatórios e nos instrumentos do planejamento urbano-ambiental. O levantamento dos indicadores morfológicos e das características hidrodinâmicas, em um primeiro momento, corresponde ao entendimento da "ameaça". No entanto, introduzir na avaliação desses impactos o significado dos agentes sociais pelos mecanismos de intervenção nos sistemas naturais é fundamental para questionar como o planejamento incorpora ou não esses resultados em suas ações de transformação do espaço urbano, incluindo os aspectos da legislação que abrangem o Código Florestal, a Lei de Recursos Hídricos, a Lei de Proteção aos Mananciais, as Áreas de Preservação Permanente (APPs). As intervenções estruturais nos sistemas fluviais, caracterizados por canalização de córregos, reservatórios de detenção, represamentos, estruturas hidráulicas (micro e macrodrenagem), sistemas viários, impermeabilização das superfícies, aterros, dentre outros, geram perturbações e modificam o comportamento dos processos da dinâmica natural, do regime hidrológico, criando novas "ameaças antropogênicas" (Vallejo, 2011), que se agravam quando ocorrem eventos extremos.

Esse cenário evidencia a complexidade dos riscos associados às inundações na RMSP e a vulnerabilidade dos seus habitantes, traduzida por registros de eventos de grande impacto, como as inundações dos rios Tietê e Pinheiros, de 2006, e do extravasamento da barragem do reservatório de Paiva Castro em 2016, que faz parte do Sistema Cantareira, afetando diretamente os municípios de Franco da Rocha e Caieiras.

Embora se verifique uma alta suscetibilidade à inundação na extensa área da região dos municípios da Baixada Santista e Litoral Norte, os riscos são restritos aos trechos representados pela alta vulnerabilidade social. 
Figura 4 - Áreas de suscetibilidade à inundação - 2019

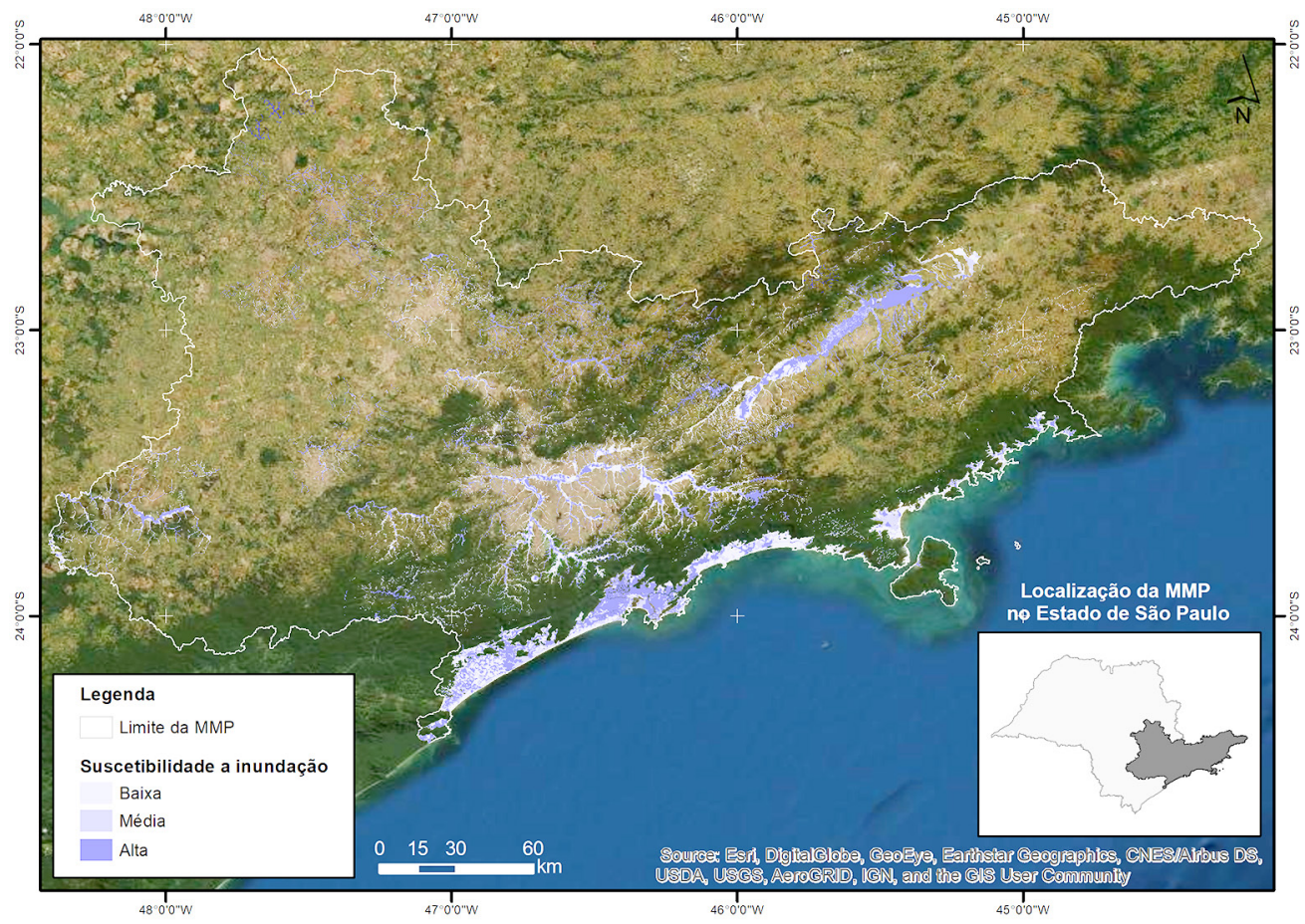

Fonte: CPRM, 2014, 2017, 2018.

0 significado da redução da vulnerabilidade e da gestão de riscos como contribuição para o planejamento de ações da MMP

O aumento de desastres nas áreas urbanas tem demonstrado que as intervenções antropogênicas sobre os sistemas naturais do espaço geográfico têm um papel preponderante nos riscos de desastre sejam eles de origem natural ou tecnológica. O agravamento das desigualdades sociais - intimamente associado à atuação do capital imobiliário no espaço urbano - tem provocado o aumento da vulnerabilidade dos grupos sociais que vivem em condições de precariedade e pobreza. Devido a sua baixa condição socioeconômica, esses grupos tendem a ocupar "espontaneamente", ou melhor, sem alternativa, partes da cidade com alto potencial de risco.

Segundo Vallejo (2011), a relação sociedade-território ainda reúne novas possibilidades para a construção social do risco, principalmente quando essa conjunção dinâmica se desenvolve sob uma diversidade de ações institucionais com sérios entraves políticos, normativos e administrativos que aumentam as desigualdades para o acesso ao uso da terra com segurança e qualidade. 
Assim, ao se tratar da análise das áreas de risco e suscetíveis aos desastres, questiona-se qual o planejamento que se pretende implementar, levando-se em conta as populações vulneráveis (vulnerabilidade social - inerente). Inclui-se aí também a necessidade de se propor uma mudança de paradigma em relação às intervenções que vêm sendo praticadas e reproduzidas dentro do modelo econômico vigente, altamente especulativo.

Ao longo do processo histórico, o planejamento sempre esteve mais voltado diretamente às prerrogativas política e econômica do território do que às sociais propriamente ditas, de modo que nem mesmo as novas concepções do desenvolvimento e da injustiça social foram suficientes para transformar essa perspectiva (Cepal, 2017) e, em certa medida, as questões de vulnerabilidade social não são encaradas com a seriedade que deveriam. Contudo, em tese, o planejamento deve primar pela formulação de uma metodologia rigorosa que viabilize uma complexa análise dos fenômenos socioespaciais. Por isso o planejamento territorial, na visão de Suárez (2011), consiste em um dos instrumentos fundamentais para a redução dos riscos: o principal objetivo para essa redução é a diminuição das fragilidades socioeconômicas, das suscetibilidades e da exposição da população, definindo níveis aceitáveis de risco.

A Agenda 2030, com os Objetivos do Desenvolvimento Sustentável (ODS), aprovada na Assembleia das Nações Unidas em 2015, fruto de discussão e compromisso políticos dos países no que tange às diversas perspectivas da vida econômica, social e ambiental da sociedade contemporânea, em seu parágrafo 76 , menciona as práticas de gestão do território:
[...] é preciso construir territórios mais articulados, integrados e coesos, por meio da elaboração e execução de planos, políticas e instrumentos de gestão territorial e urbana, concebidos de forma participativa, com uma visão centrada na população, no âmbito dos direitos humanos e com a perspectiva de gênero e um enfoque de sustentabilidade e gestão de riscos ambientais. (Cepal, 2017)

Também na reunião do Marco de Sendai (Redução de Riscos 2015-2030), realizada no Japão em 2015, assim como no Habitat III (Conferência sobre habitação e desenvolvimento urbano sustentável), realizado no Equador em 2016, ficou claro o incentivo para maior coordenação e cooperação entre os governos nacional (federal), subnacional (estadual) e local (municipal), para definir as respectivas competências, instrumentos e recursos destinados a cada um dos níveis de governo (UNISDR, 2015).

Ainda de acordo com o Marco de Sendai, no âmbito da questão da escala, são definidas quatro prioridades de ação para a gestão de riscos: compreensão do risco de desastres; governança e gerenciamento de riscos de desastres; investimentos e redução de riscos de desastres; e maior prontidão para resposta e reabilitação.

Como, então, considerar as prioridades de ação do Marco de Sendai no planejamento territorial e dos ODSs, sobretudo o ODS 11 ,

relacionado às cidades e os assentamentos humanos inclusivos, seguros, resilientes e sustentáveis, considerando o acesso de todos à habitação adequada e aos serviços básicos, 
associados a espaços públicos seguros, particularmente para as crianças e pessoas idosas, agregando, ainda, pessoas com deficiência

e o ODS 6, "água e saneamento para todos, envolvendo a proteção e restauração de ecossistemas condizentes a essa questão, apoiando e fortalecendo a participação das comunidades locais, para melhorar sua gestão"? No Brasil, a própria PNPDEC prevê que a gestão de riscos e de desastres abranja vários campos do conhecimento, enfatizando a necessidade da articulação com outras políticas públicas, estabelecida entre a União, os Estados, o Distrito Federal e os municípios para redução de desastres e apoio às comunidades atingidas (Canil et al., 2019).

Conforme o exemplo apresentado sobre o problema das inundações na região da MMP, confirma-se a existência de vários trabalhos que buscam representar espacialmente as áreas suscetíveis a essa ameaça ou perigo, ou seja, do processo hidrológico, assim como os territórios de vulnerabilidade social. Ao planejamento, caberá incorporar esses produtos para compreensão das dinâmicas do território em sua totalidade. Isso vem refletir recentemente o Plano de Desenvolvimento Urbano Integrado da região Metropolitana de São Paulo (um dos instrumentos do Estatuto da Metrópole), elaborado com base no processo permanente de planejamento, viabilização econômico-financeira e gestão, diretrizes, projetos e ações para orientar o desenvolvimento territorial urbano e regional estratégico das regiões metropolitanas e/ou aglomerações urbanas brasileiras (ibid.). Esse plano contempla a Gestão de Riscos como uma das estratégias para a gestão metropolitana, a qual inicialmente não estava prevista, integrando suas ações e diretrizes às questões ambientais e à precariedade habitacional (Emplasa, 2018). Essa proposta também está sendo levada para as outras regiões metropolitanas que estão desenvolvendo os seus PDUls.

\section{Considerações finais}

0 reconhecimento de que o território da MMP é caracterizado por expressivas áreas e situações de risco, com destaque no artigo para os riscos associados às inundações, aponta para a necessidade urgente de definir Políticas e Planos de Desenvolvimento social para reduzir a vulnerabilidade das populações expostas aos riscos, como parte do desenvolvimento sustentável (redução da pobreza, melhoria da saúde, serviços, etc. nas áreas de risco, criação de oportunidade de emprego para a população das comunidades vulneráveis, aumento da oferta de educação). São ações no âmbito da prevenção e do planejamento que fazem parte de uma efetiva gestão de riscos, que está para além dos atendimentos às emergências e aos desastres.

Essas ações, sejam elas implementadas a partir de boas práticas ou a partir de experiências locais, necessitam de políticas governamentais de suporte, e, portanto, a gestão de riscos deve se tornar mais relevante como elemento de nexo entre políticas fundiárias, instrumentos de planejamento urbano, participação social e vontade política, para de fato exercer uma ação coletiva e traçar estratégias que tratem das injustiças socioambientais e da redução das vulnerabilidades.

A proposta da sistematização dos principais enfoques da vulnerabilidade (Risco - Ameaça; Construção Social do Risco e 
Abordagem Sistêmica) discutida neste artigo é uma abordagem que deve ser utilizada pelos métodos de planejamento, valendo-se da leitura do território em sua integralidade, estabecelendo cenários futuros a partir da compreensão das ameaças, que em grande parte tem seus efeitos mais catastróficos, pelas intervenções antropogênicas que desconsideram tanto a dinâmica da natureza, em se tratando das grandes obras urbanas, quanto os efeitos da segregação socioespacial formando territórios de de exclusão em condições de risco permanente em grande parte das cidades que fazem parte das MMP.

\section{[1] https://orcid.org/0000-0001-9599-3903}

Universidade Federal do ABC, Centro de Engenharia, Modelagem e Ciências Sociais Aplicadas, Programa de Pós-Graduação em Planejamento e Gestão do Território. Santo André, SP/Brasil.

katia.canil@ufabc.edu.br

\section{[II] https://orcid.org/0000-0002-1561-5409}

Universidade de São Paulo, Instituto de Energia e Ambiente, Programa de Pós-Graduação em Energia. São Paulo, SP/Brasil.

alampis@usp.br

\section{[III] https://orcid.org/0000-0001-9996-1079}

Universidade de São Paulo, Instituto de Energia e Ambiente, Programa de Pós-Graduação em Energia. São Paulo, SP/Brasil.

kaue.santos@usp.br

\section{Nota de agradecimento}

Os autores Andrea Lampis e Kauê Lopes dos Santos agradecem o apoio da Fundação de Amparo à Pesquisa do Estado de São Paulo (Fapesp) (processos n. [2018/17626-3] e [2017/22067-0]). Este trabalho é parte das atividades do projeto temático, em andamento, "Governança ambiental na Macrometrópole Paulista, face à variabilidade climática”, processo no 15/03804-9, financiado pela Fapesp e vinculado ao Programa Fapesp de Pesquisa sobre Mudanças Climáticas Globais.

\section{Nota}

(1) O conceito da vulnerabilidade biofísica e social refere-se ao uso do conceito nas políticas públicas, de modo que as terminologias "resultantes" e "inerentes" tratam da conceitualização mais abstrata dos conceitos empregados e podem ser encontradas na ecologia ou na teoria dos sistemas. 


\section{Referências}

ADGER, W. N. (2006). Vulnerability. Global Environmental Change, v. 16, pp. 268-281.

BLAIKIE, P. et al. (1994). At risk: natural hazards, people's vulnerability and disasters. Londres, Routledge.

(1996). Vulnerabilidad: el entorno social, político económico de los desastres. Bogotá, La Red.

BROOKS, N. (2003). Vulnerability, risk and adaptation a conceptual framework. Working Paper. Norwich, University of East Anglia.

BRASIL (2001). Lei federal n. 10.257/2001 - Estatuto da Cidade. Brasília. Disponível em: http://www. planalto.gov.br/ccivil_03/leis/LEIS_2001/L10257.htm. Acesso em: 10 out 2019.

(2012). Lei federal n. 12.608 - Política Nacional de Proteção e Defesa Civil - PNPDEC. Brasília. Disponível em: http://www.planalto.gov.br/ccivil_03/_Ato2011-2014/2012/Lei/L12608.htm. Acesso em: 10 out 2019.

(2015). Lei federal n. 13.089/2015 - Estatuto da Metrópole. Brasília. Disponível em: http:// www.planalto.gov.br/ccivil_03/_Ato2015-2018/2015/Lei/L13089.htm. Acesso em: 10 out 2019.

CANIL, K.; MYAMOTO, M. M.; FIGUEIRA, R. M. e TOMBETA, L. R. (2019). Gestão de riscos e desastres e a articulação com o Plano de Desenvolvimento Urbano Integrado: ações para uma governança da Região Metropolitana de São Paulo. In: XVIII ENANPUR. Anais... Natal.

CEPAL (2017). La Medición Multidimensional De La Pobreza. In: DUODÉCIMA REUNIÓN DEL COMITÉ EJECUTIVO DE LA CONFERENCIA ESTADÍSTICA DE LAS AMÉRICAS DE LA COMISIÓN ECONÓMICA PARA AMÉRICA LATINA Y EL CARIBE. Anais... Pucón.

CHARDON, A. C. (2010). Reasentar un hábitat vulnerable. Teoría versus praxis. Revista INVI, v. 25, n. 70, pp. 17-75.

DICKSON, F. et al. (2012). Urban risk assessment: understanding disaster and climate change in cities. Washington, DC, Word Bank. Disponível em: http://www.worldbank.org. Acesso em: 10 out 2019.

DURHAM, E. R. (2004). A dinâmica cultural. São Paulo, Cosac Naify.

EMPLASA-EMPRESAPAULISTADEPLANEJAMENTOMETROPOLITANO(2018).Plano de Desenvolvimento Urbano Integrado. Região Metropolitana de São Paulo. Caderno final Propostas. Disponível em: https://www.pdui.sp.gov.br/rmsp/?page_id=755. Acesso em: 10 out 2019.

(2019). Disponível em: https://www.emplasa.sp.gov.br/RMSP. Acesso em: 10 maio 2019.

FERREIRA, J. S. W. (2007). O mito da cidade global: o papel da ideologia na produção do espaço urbano. Petrópolis, Vozes/ São Paulo, Editora Unesp/ Salvador, Anpur.

FURTADO, C. (1976). A economia latino-americana. São Paulo, Nacional.

FÜSSEL, H. M. (2010). How inequitable is the global distribution of responsibility, capability, and vulnerability to climate change: A comprehensive indicator-based assessment. Global Environmental Change, v. 20, n. 4, pp. 597-611.

FÜSSEL, H. M. et al. (2017). Climate change, impacts and vulnerability in Europe 2016 - An indicator-based report, v. 1, s.l, s.n. 
IPCC - INTERGOVERNMENTAL PANEL ON CLIMATE CHANGE (2012). Disponível em: https://www.ipcc. ch. Acesso em: 10 out 2019.

JACOBI, P. R.; CIBIM, J. e LEÃO, R. S. (2015). Crise hídrica na Macrometrópole Paulista e respostas da sociedade civil. Estudos Avançados, v. 29, n. 84. São Paulo.

KOWARICK, L. (2009). Viver em risco: sobre a vulnerabilidade socioeconômica e civil. São Paulo, Ed. 34.

LAMPIS, A. (2013). Vulnerabilidad y adaptación al cambio climático: debates acerca del concepto de vulnerabilidad y su medición. Revista Colombiana de Geografía, v. 22, n. 2, pp. 17-33.

LAMPIS, A. (2017). "Concepts, connections and disruptions: DRR and CCA". In: KELMAN, I.; MERCER, J. e WISNER, B. (eds.). Routledge handbook of disaster risk reduction including climate change adaptation. Londres e Nova York, Routledge.

LENCIONI, S. (2015). Urbanização difusa e a constituição de megarregiões. O caso de São Paulo - Rio de Janeiro. @Metropolis. Revista Eletrônica de Estudos Urbanos e Regionais, n. 22, pp. 6-15.

LONDE, L. D. R. et al. (2018). Vulnerability, health and disasters in São Paulo coast (Brazil): challenges for a sustainable development. Ambiente \& Sociedade, v. 21, n. 0.

MAMIGONIAN, A. (1999). Teorias sobre a Industrialização brasileira. Cadernos geográficos, n. 2. Florianópolis.

MARCHEZINI, V.; WISNER, B; LONDE, L. R. e SAITO, S. M. (orgs.) (2017). Reduction of vulnerability to disasters: from knowledge to action. São Carlos, RiMa.

MARICATO, E. (1996). Metrópole na periferia do capitalismo. São Paulo, Hucitec.

MARTINS, M. L. R. (2006). Moradia e mananciais: tensão e diálogo na metrópole. São Paulo, FAUUSP e Fapesp.

MOURA, R. B.; CANIL, K. e SULAIMAN, S. N. (2019). Vulnerabilidade social, suscetibilidade e riscos de deslizamentos: Um estudo sobre a Macrometrópole Paulista. In: ENCONTRO NACIONAL DA ANPEGE, 13. Anais.... São Paulo.

NEUMAYER, E.; PLUMPER, T. e BARTHEL, F. (2014). The Political Economy of Natural Disaster Damage. Global Environmental Change, 24, pp. 8-19. Disponível em: http://ssrn.com/abstract=1884827. Acesso em: 10 out 2019.

OLIVER-SMITH, A. (1991). Successes and Failures in post-disaster resettlement. Disasters, v. 15, issue 1.

PASTERNACK, S. e BÓGUS, L. M. (2019). Macrometrópole Paulista: estrutura sócio-ocupacional e tipologia dos municípios - mudanças na primeira década dos anos 2000. Revista Brasileira de Estudos Urbanos e Regionais, v. 21, n. 2. São Paulo.

RANGEL, I. (1985). Economia: milagre e anti-milagre. Rio de Janeiro, Zahar.

RICHTER, R. M. e JACOBI, P. R. (2018). Conflitos na macrometrópole Paulista pela perspectiva da crise hídrica. Revista Brasileira de Estudos Urbanos e Regionais, v. 20, n. 3.São Paulo.

RODRIGUES, C. (2015). Atributos ambientais no ordenamento territorial urbano: o exemplo das planícies fluviais na metrópole de São Paulo. Geousp - Espaço e Tempo (On-line), v. 19, n. 2, pp. 325-348. Disponível em: doi: http://dx.doi.org/10.11606/issn.2179-0892. geousp.2015.102805.

ROLNIK, R. (1998). A cidade e a lei: legislação, política urbana e territórios na cidade de São Paulo. São Paulo Fapesp e Studio Nobel. 
ROSS, J. e MOROZ, I. (2011). Mapa geomorfológico do estado de São Paulo. Revista do Departamento de Geografia, 10, pp. 41-58.

SANTOS, M. e SILVEIRA, M. L. (2001). O Brasil: território e sociedade no início do século XXI. Rio de Janeiro, Record.

SASSEN, S. (2014). Expulsions: brutality and complexity in the global economy. Cambridge e Londres, Harvard University Press.

SUÁREZ, D-C. (2011). Disaster risk reduction in Latin America, improving tools and methods regarding climate change: the case study of Colombia and the city of Manizales. Manizales, National University of Colombia in Manizales, Institute of Environmental Studies.

TAVARES, J. (2018). Formação da macrometrópole no Brasil: Construção teórica e conceitual de uma religião de planejamento. EURE, v. 11, n. 133. Santiago.

UNISDR - International Strategy for Disaster Reduction (2015). Sendai Framework for Disaster Risk Reduction 2015-2030. Disponível em: https://goo.gl/gmD3D7. Acesso em: 10 out 2019.

(2019). Protocolo parlamentar para a redução do risco de desastres e adaptação às alterações climáticas: alinhado com o Marco de Sendai para a redução do risco de desastres 2015-2030. Disponível em: https://parlamericas.org/uploads/documents/POR_Protocolo_DRR_Online_ Version.pdf. Acesso em: 10 out 2019.

UNITED NATIONS (2019). A/RES/70/1 - Transforming our world: the 2030 Agenda for Sustainable Development. Disponível em: https://goo.gl/s3RAhp. Acesso em: 10 out 2019.

VALLEJO, H. B. (2011). Suelo urbano, vulnerabilidad y riesgo de desastres. Caso de estúdio: Región Metropolitana de Cochabamba, Bolívia. Cochabamba.

VILLAÇA, F. (1998). Espaço intra-urbano no Brasil. São Paulo, Studio Nobel/ Fapesp/Lincoln Institute.

Texto recebido em 31/out/2019

Texto aprovado em 15/jan/2020 